\title{
0 jornalismo de economia e a ditadura militar no Brasil: impulso e desenvolvimento
}

\section{RESUMO}

Este artigo aborda o jornalismo de economia no período da ditadura militar no Brasil a partir das seguintes questões: Como esse jornalismo estava situado dentro do contexto do regime militar? Por que conseguiu se desenvolver nesse período? Levantamento bibliográfico e relatos de jornalistas de referência, que atuaram na área, ajudam a traçar a trajetória dessa cobertura nessa fase. Esta abordagem faz parte de uma pesquisa mais ampla sobre o jornalismo de economia no final do século XX - que resultou em uma tese defendida no Doutorado de Comunicação e Cultura da UFRJ em fevereiro de 2009.

\section{PALAVRAS-ChaVE}

Jornalismo de economia

Ditadura Militar

Desenvolvimento

Economy journalism and the military dictatorship in Brazil: impulse and development

\section{ABSTRACT}

This paper approaches the economy journalism during the military dictatorship in Brazil from the following questions: How this journalism was situated inside of the context of the military regimen? Why it developed in this period? Bibliographical survey and interviews with reference journalists, who had acted in this area, help to trace the trajectory of this covering in this phase. This boarding is part of a wide research - about economy journalism in the end of century XX - that resulted in a thesis defended in the $\mathrm{PhD}$ in Communication and Culture of UFRJ in February of 2009.

\section{KEYWORDS}

Economy journalism

Military dictatorship

Development

\section{Hérica Lene}

Professora do Departamento de Ciências da Informação da UFES/ES/ $B R$

Hericalene@yahoo.com.br
O jornalismo de economia tem uma larga tradição no Brasil. Os veículos de comunicação voltados para a indústria, o comércio e os negócios de maneira geral, surgiram em todo o país em meados do século XIX. Esse tipo de cobertura foi consolidada ao longo do século seguinte.

Como registramos em abordagem anterior (Lene, 2004), a difusão generalizada desse jornalismo especializado na grande imprensa do país está intimamente ligada à reorganização do capitalismo em escala mundial e ao seu desdobramento na economia brasileira a partir da década de 1950. Naquela época, a cobertura dessa área revelava-se incipiente, conforme mostram pelo menos três autores que desenvolveram estudos sobre o tema: Aylê-Salassiê Figueiras Quintão (1987), Nancy Nuyen Ali Ramandan (1995) e Samantha Carvalho (2001). Ela se fortaleceu, principalmente, a partir do final da década de 1960, e se identificava com o modelo de desenvolvimento econômico do Brasil.

Nas duas décadas seguintes, o jornalismo de economia foi se ampliando. Neste artigo ${ }^{1}$, discute-se seu desenvolvimento no período da ditadura militar no Brasil a partir das seguintes questões: Como estava situado dentro do contexto do regime militar? Por que conseguiu se desenvolver nesse período? Levantamento bibliográfico e relatos de jornalistas de referência que atuaram na área ajudam a traçar a trajetória dessa cobertura nessa fase, que é o objetivo desta abordagem. ${ }^{2}$

Estímulos ao crescimento

A década de 1960 ficou marcada pelo Golpe Militar de 1964, que trouxe com ele o Estado de exceção, regulado pelos atos institucionais, editados no âmbito do Executivo, sob o comando dos militares. Os partidos políticos foram extintos e políticos, jornalistas e cidadãos cassados ou perseguidos pela repressão. Novas leis de segurança nacional e de imprensa foram editadas, inclusive algumas, para fortalecer o papel da censura.

O Golpe de 1964, que significou uma ruptura política com o populismo e o aprofundamento das tendências econômicas pré-existentes, forneceu a moldura para algumas transformações expressivas na sociedade e nos rumos do capitalismo brasileiro. O período se caracterizou pela crescente participação do 
Estado na economia e pela ampliação das atribuições do Executivo em detrimento dos demais poderes e de canais de representação política. Aprofundou-se a interdependência entre o político e o econômico (Mendonça \& Fontes, 1994, p. 5-6).

No período imediatamente posterior ao Golpe Militar, a economia foi submetida a um duro e eficiente processo de modernização, conduzido pela dupla Roberto Campos e Octávio Gouvêa de Bulhões, respectivamente ministros da Fazenda e do Planejamento. Criou-se o Banco Central (BC); reestruturou-se o sistema financeiro; instituiu-se a correção monetária, o que viabilizou os financiamentos de longo prazo, e as minidesvalorizações cambiais, o que garantiu as exportações; montou-se o Banco Nacional da Habitação (BNH), como forma de incentivo à construção civil. E os salários foram achatados, a fim de se combater uma inflação que chegara à casa dos 100\% ao ano (Nassif, 1986, p. 42).

No período pós-1964, foram criados mecanismos de incentivo à entrada de moeda estrangeira no país, para facilitar a remessa de lucros, e oferecidos, para exploração, recursos naturais em abundância, mão-deobra barata e um mercado consumidor potencialmente amplo.

Foi também nessa década que começou a se tornar perceptível a formação de uma indústria cultural no Brasil no sentido mais estrito do termo, isto é, um sistema de complexos empresariais ligados ao setor da chamada comunicação de massa (Taschner, 1992, p. 103).

Ocorreu, nessa época, a expansão do jornalismo - e não só dos jornais, revistas, rádios e televisão, mas também do livro, do disco, da música e do teatro que estimulou a formação de cadeias e redes nacionais e regionais de comunicação (Bahia, 1990, p. 267). Mas essa ampliação se deu dentro de um processo de concentração empresarial, iniciado nos anos 1950 e que se acirraria nas duas décadas seguintes. ${ }^{3}$ Do ponto de vista econômico, foi resultado de uma aguda crise pela qual passou a imprensa, devido a um conjunto de fatores, como a queda do volume de publicidade (no período de 1960 a 1963), o desenvolvimento da televisão (que, ao se popularizar, a partir dos anos 1960, passou a atrair fatias cada vez maiores do bolo publicitário) e os problemas com o papel (sobretudo no período 1957-1975). Além disso, o início dos anos 1960 foi marcado por uma crise econômica geral, com altas taxas de inflação (Ribeiro, 2007, p. 208).

O jornalista Joelmir Beting, que começou a trabalhar com jornalismo de economia em 1962, relembra que, à época, essa cobertura era muito restrita e ocupava pouco espaço nas páginas dos grandes jornais:

O jornalismo econômico separava o turfe dos classificados nos jornais, e ia depois do futebol. O espaço era uma página, uma página e meia, nos grandes jornais do Brasil, que eram o Jornal do Brasil, O Globo, Estado, a Folha, e alguns jornais especializados, mas também de baixa circulação e também pouco prestígio político, o Jornal do Commercio e a Gazeta Mercantil. Tinha aqui em São Paulo também a revista Visão, que era mais especializada em economia, e nada além disso.

Além de ter uma pauta restrita, a produção da editoria de economia, nos grandes jornais, nos anos 1960, ficava mais por conta de economistas do que de jornalistas, conforme ele relata:

Havia no jornalismo econômico uma espécie de gueto que era operado por economistas e não por jornalistas. Além de pouco espaço, esse espaço era ocupado por economistas convidados até no "peito", pois não cobravam nada para escrever. Então, escreviam um artigo sobre a crise do café, outro sobre o câmbio, outro sobre política cambial. Não havia jornalismo econômico praticamente no Brasil. Aí, juntamente com Aloysio Biondi ${ }^{4}$, que foi para o Rio de Janeiro e deu uma sacudida no Correio da Manhã e começou a dar um tratamento muito importante ao noticiário econômico e ao debate econômico no Correio da Manbã, eu fiz um trabalho parecido com a Folha de S. Paulo. E aí nós fomos formando, eu e ele, uma geração de jornalistas econômicos no Rio e eu uma geração em São Paulo. E ele como editor e eu também como editor. E ele chegou a ser editor do próprio jornal, além de editor de economia lá no Rio. Depois viria para São Paulo para levantar a revista Visão e deu um choque de qualidade muito grande nela.

Durante o regime militar, a editoria de economia dos jornais se expandiu. O discurso oficial do governo concentrava-se em tecer elogios aos seus feitos na área econômica. Essa era a postura que deveria engajar as assessorias e os programas oficiais. Os jornalistas que trabalhavam no serviço público e as assessorias de 
imprensa passaram a ser chefiadas por militares, ou por civis identificados com os princípios básicos do Golpe de 1964 e que contribuíram para ele.

Esse discurso oficial era dirigido principalmente à classe média, cuja renda crescia na época, e também aos segmentos sociais com poder de barganha política. Fundamentava-se na informação de economia e apoiavase nos diversos indicadores de crescimento, na palavra e cálculos econométricos dos tecnocratas e em uma censura violenta aos meios de comunicação. Apregoavase a paz social, a recuperação econômica e o "milagre do crescimento" (Quintão, 1987, p. 71).

Beting relembra essa expansão da cobertura de economia ao longo do regime militar e a criação de sua coluna sobre a área econômica nesse período:

Todos os jornais começaram a descobrir que havia ali um filão, chamado informação econômica, que o brasileiro já estava de olho gordo nele. Enquanto a informação econômica estava decolando, estava aterrissando a informação política, que estava já sob controle. Então, esvazia a informação política e cresce a econômica. E a informação econômica acaba ganhando uma dimensão política até no vácuo da própria informação política. Aí o debate econômico virou um debate político, de opções e alternativas e críticas e, então, o debate político deslocou-se para a área econômica. E a gente estava no meio desse tiroteio, eu como editor da Folha e depois também como colunista. Passei a fazer a coluna diária, que duraria 33 anos de publicação diária, até acabar por fadiga de material, comigo (risos). Então foi tudo ali pelo final dos anos 1970, dos anos 1960.

O jornalista destaca, em seu relato, a dimensão política que a notícia de economia foi ganhando nesse período.

\section{A fase de censura aos meios de comunicação atingiv também a cobertura de economia, mas não de uma forma incisiva, como ocorreu no noticiário político,}

segundo complementa Beting:

Depois veio o AI-5 e tornou a informação econômica um pouco mais monitorada pelos jornais, não era pelos jornalistas, mas pelos jornais, porque estavam sob pressão do regime militar. Então, certos debates eram interditados não pela censura, porque não havia uma censura formal ainda, mas eram monitorados através das editorias, dos donos dos jornais. Houve um pacto entre eles de não cutucar a onça com vara curta. E depois acabou vindo a censura de vez e, em seguida, pegou todo o noticiário político e econômico. $\mathrm{E}$ foi aquele período triste lá. Agora, na economia, em compensação, nesse momento de escuridão política, houve uma explosão com o chamado "milagre econômico brasileiro", o que deu outra dimensão, ainda maior, à informação econômica. Por exemplo, em 1970, a economia passou a crescer quase $10 \%$ ano, o governo lançou grandes projetos, de Brasil potência, houve um 'boom' no mercado de capitais, nas Bolsas do Rio e São Paulo - a do Rio de Janeiro era o dobro da de São Paulo na época -, houve até aquela grande bolha especulativa, mas que era notícia. Motorista de táxi queria saber o que a gente estava achando das ações do grupo Ipiranga nas Bolsas, por exemplo. Quando? Em 1970. Então, aí é que aconteceu o seguinte: com o jornalismo dando esse segundo salto e o milagre econômico de 1970/1971 e 1972, as outras mídias, como rádio e TV, começaram a pensar no caso e a trazer a informação econômica para o rádio e para a TV.

E o crescimento econômico, em seus diversos segmentos, passou a ser tema preponderante de encontros, seminários, visitas, entrevistas, viagens, inaugurações e discussões políticas. Os jornais de cobertura geral e grandes tiragens começaram a cobrir esses eventos, a acompanhar e difundir negócios, o movimento do mercado de capitais $^{6} \mathrm{e}$ as decisões do Conselho Monetário Nacional (CMN). Algumas reportagens abriram espaços para empresas (Quintão, 1987, p. 74). 
Outro jornalista que atua na cobertura jornalística e na análise dessa área na imprensa brasileira, Carlos Alberto Sardenberg ${ }^{7}$, também destaca que o jornalismo de economia do país é contemporâneo do período da ditadura de 1964-1985 e que se formou e adquiriu solidez nessa época por razões estruturais e históricas:

O regime militar tinha como doutrina básica a busca do desenvolvimento. Pregava-se que o país precisava ter determinadas condições políticas - as de um regime autoritário - para que isso permitisse um crescimento acelerado. Também se dizia que não era possível ter uma prática democrática ou um país civilizado, de primeiro mundo, sem uma base econômica sólida. Não era uma teoria brasileira, mas espalhada pelo mundo afora, pois houve governos semelhantes em diversos outros países, todos com a mesma ideia e o mesmo objetivo básico. Isso criou uma demanda concreta para o jornalismo, mesmo porque, se olharmos a história do regime militar, veremos que ele teve dois grandes êxitos nessa área. O primeiro esteve representado pelos processos de ajuste da economia e de reforma do setor público, no governo Castelo Branco (19641967). O setor público, que se deteriora ao longo do tempo, foi totalmente remodelado e tornou-se muito mais eficiente e competente. Criaram-se o Banco Central, o BNH, o sistema de controle das estatais, o orçamento monetário... Imprimiu-se um novo caráter ao BNDES. Enfim, houve uma série de medidas importantes, que arrumaram e modernizaram o setor público. $\mathrm{O}$ segundo sucesso, obviamente, ficaria patente no " $\mathrm{mi}$ lagre econômico" e nas taxas de crescimento de $14 \%$ ao ano, que colocavam o Brasil na ponta dos países que se desenvolviam. ${ }^{8}$

A marca do aparecimento do jornalismo de economia, nos moldes como passou a ser praticado no final do século XX, tem a influência de um encarte do Correio da Manhã, o Diretor Econômico. Com 16 páginas diárias, dedicadas ao tratamento dos negócios no mercado, e por meio de reportagens sobre as empresas e o acompanhamento sistemático dos negócios, demonstrou que qualquer cidadão poderia aplicar em Bolsa de Valores, não apenas os iniciados, e chamou a atenção dos pequenos e grandes investidores para isso (Quintão, 1987, p. 74-77).

A linha editorial do Diretor Econômico era, de acordo com Quintão (1987, p.78), “crítica, esclarecedora do mercado e denunciadora das práticas contábeis maliciosas das empresas ou do governo". Muitas matérias esclareceram ao público fatos que o governo queria esconder sobre a política econômica, e isso desagradou o então ministro Delfim Neto, que fez pressão para que o caderno fosse extinto. Ao sair do mercado, o Diretor Econômico despertou os periódicos para o espaço editorial que acabara de deixar. Rapidamente, os grandes jornais começaram a multiplicar páginas de cobertura da área econômica.

Havia uma diferença significativa entre o jornalismo de economia do Diretor Econômico e o que foi desenvolvido pelos grandes jornais. O Diretor fazia uma cobertura de negócios. Já o noticiário e a análise econômica, na grande imprensa na década de 1970, estavam preocupados com o discurso da sociedade política, no exercício do poder, endereçado à sociedade civil (Quintão, 1987, p. 79).

Sobre o crescimento de publicações específicas da área de economia nessa época, é importante registrar que:

O novo noticiário econômico não tratará de questões polêmicas. Abordará, numa direção positiva, grandes operações financeiras internas ou externas, insistirá na abertura de capitais por empresas tradicionais, em novas linhas de produção industrial, ou questões ligadas à agropecuária, avançando em discussões meramente acadêmicas de categorias simbólicas da ciência econômica, como o comportamento dos agregados macroeconômicos, tipo crescimento do PIB, a composição do Balanço de Pagamentos, da Balança Comercial ou das contas correntes; discussão sobre fórmulas de análise dos componentes inflacionários; fluxo dos meios de pagamento, dos investimentos globais; discutirá o déficit público, o open market e até mesmo práticas econômicas desconhecidas no Brasil (Quintão 1987, p. 79).

Outros temas abordados por anos seguidos foram as correntes do pensamento econômico e a inflação brasileira. Esses assuntos refletiam as mudanças 
introduzidas na economia do país e foram discutidos em editoriais, pelos articulistas, por comentaristas econômicos que começavam a surgir e no próprio noticiário, em entrevistas com economistas e empresários.

Nos anos 1970, o jornalismo de economia continuou seu processo de ampliação. Até essa década, o noticiário era essencialmente financeiro/comercial, voltado para informações práticas: cotações da Bolsa, informações sobre câmbio, entrada e saída de navios, preços e produção de produtos agrícolas. Depois, passou a ter mais destaque, não só porque as notícias sobre política sofriam forte censura, mas também porque a economia havia se tornado um dos temas centrais do regime militar.

O jornalista Luís Nassif, que começou a atuar como repórter de economia em 1974, destaca qual era a principal característica do jornalismo dessa área nessa fase:

Era muito "oficialesco". Você escrevia para o empresário e para o economista. Havia um abuso da terminologia técnica e muito pouco conhecimento sobre o que significavam os termos técnicos. O leitor comum era ignorado. Principalmente os mecanismos da economia não eram decifrados para o leitor. Você tinha o Joelmir Beting que, na época, já usava uma linguagem mais acessível, mas ele não entrava na explicação dos fundamentos da economia. E teve um período, nos anos 1980, em que a economia foi muito utilizada para manipulação política. Isso no final do regime militar. Quando você teve o fim da censura na Veja, a economia não teve uma matéria censurada. Os jornais eram contra, digamos, o regime político, mas no plano econômico não havia discordância.

Alzira Alves de Abreu (2003, p.14-23), ao buscar entender a transição política brasileira a partir do papel desempenhado pela imprensa escrita nesse processo, afirma que a repressão e a censura estimularam a escolha da profissão de jornalista por parte de jovens engajados politicamente. Dessa forma, o jornalismo acabava sendo não só uma profissão, mas um canal de ação política. Dentro das redações, boa parte desses jovens engajados optou por trabalhar nas editorias de economia, criadas durante a ditadura militar. Afinal, na visão desses militantes de esquerda, influenciados pelo marxismo e pela linha de atuação do Partido Comunista Brasileiro (PCB), as explicações econômicas superavam todas as demais.

\section{O fortalecimento da economia e dos economistas}

\section{Na trajetória de mudanças ocorridas durante o regime militar, os economistas passaram a ter o papel e 0 espaço que antes eram dados à política e aos políticos.}

Os militares, em nome da eficiência econômica e da competência técnica, deram aos economistas os cargos de direção nos órgãos públicos, nos quais eles exerceram o poder de definir as políticas públicas e as orientações básicas para o desenvolvimento brasileiro. Eles atuaram praticamente como dirigentes políticos, mas sem as obrigações exigidas de um representante detentor de mandato eleitoral, pois não precisavam prestar contas de seus atos a um partido ou ao eleitorado (Abreu, 2001, p. 2).

Ao estudar como e por que os economistas se tornaram atores políticos importantes para o país, Maria Rita Loureiro (1997) parte do pressuposto que a posição deles, como dirigentes políticos no Brasil, não é um produto "natural", decorrente do intervencionismo e da regulação econômica que caracterizam o Estado no período contemporâneo. Mas é resultado de uma combinação complexa de fatores: passa pela estrutura de poder e pelas formas de organização do aparato governamental e inclui os vínculos entre os meios acadêmicos (responsáveis pela formação da elite dirigente) e o governo. "O segmento específico das elites dirigentes no Brasil é aquele que se identifica e se legitima não pela representação partidária e eleitoral e sim pela competência técnico-científica" (Loureiro, 1997, p. 49).

Vários fatores respondem pelo crescimento da autoridade e da influência dos economistas. Em primeiro lugar, uma espécie de síndrome de crise econômica motivou, desde a depressão dos anos 1930, a ascensão dos economistas, vistos como os portadores de instrumentos capazes de produzir resultados práticos na economia e de elaborar planos para o futuro. Em 
segundo lugar, o papel central desempenhado pelos problemas econômicos tem convertido em processo contagioso a participação deles no governo. A presença de economistas em um ministério, especialmente naquele mais estrategicamente localizado no centro do processo decisório, garante frequentemente a rápida proliferação desses profissionais por todos os lados. $\mathrm{O}$ papel que ocupam no governo tem mais a ver com a necessidade de legitimação política do que propriamente com determinações de eficiência (Loureiro, 1997, p. 3-4).

Os economistas têm participado ativamente de órgãos governamentais e influenciado de modo marcante as decisões políticas no Brasil. O processo costuma ser relacionado, com razão, à tendência mais ampla de regulação e intervenção estatal na economia, predominante na maioria dos países capitalistas a partir da II Guerra Mundial. Como, até a depressão dos anos 1930, o Estado não intervinha e apenas garantia a operação do mercado, não existia razão para que interesses privados procurassem controlar o Estado. Quando ocorreu a revolução keynesiana, o Estado adquiriu a capacidade de administrar/intervir na economia e esse processo o tornou potencialmente mais fraco e suscetível às pressões sociais (Loureiro, 1997, p. 2-6).

Foi durante o regime militar que essa categoria se fortaleceu, inclusive com a melhoria dos cursos de formação específica. O que se observa é que a instalação dos programas de pós-graduação, a expansão dos cursos de economia e do número de alunos, o crescimento da produção acadêmica, o desenvolvimento de um quadro institucional de pesquisa e, inclusive, a criação de novas revistas especializadas, são componentes de um mesmo e mais amplo processo, que se pode definir como modernização (internacionalização ou "americanização") da ciência econômica no Brasil.

A participação dos economistas no governo cresceu enormemente a partir do regime militar. A intensificação da centralização política, a hipertrofia do Poder Executivo e de seus braços de controle econômico e, ainda, a necessidade de legitimação do autoritarismo por meio da eficiência econômica fizeram aumentar o número de postos de governo praticamente monopolizados por eles. A partir de 1964, dez entre 18 ministros da Fazenda eram economistas; desde 1963, quando foi criada a Secretaria (ou Ministério) do Planejamento, seis entre sete ministros também o eram (Loureiro, 1997, p. 84).

\section{Considerações Finais}

A "cultura" de valorização da economia e dos economistas no país, consolidada durante a ditadura, acabou se estendendo também aos jornais - bem como ao jornalismo e aos jornalistas dessa área. Os repórteres dessa editoria continuaram a desfrutar de grande prestígio nas redações e o noticiário econômico permaneceu ocupando importantes espaços na imprensa, inclusive com aumento do número de páginas dos cadernos dedicados aos temas desse campo (Abreu, 2003, p. 64).

Pesquisas por amostragem demonstram que, entre 1968 e 1988, o espaço dedicado à economia pelos três principais jornais de São Paulo cresceu continuamente de 1,5 páginas diária em média para 6,5 páginas, à custa das demais áreas de cobertura. Um quinto das manchetes foi dedicado aos assuntos econômicos e os nomes dos ministros de economia tornaram-se mais populares e mais citados do que os dos presidentes (Kucinski, 2000, p. 16). ${ }^{?}$

O modelo de desenvolvimento econômico adotado no Brasil a partir do final dos anos 1960 também abriu espaço para o aparecimento e desenvolvimento de um grande número de boletins (news letters) e revistas especializadas em economia (Quintão, 1987, p. 83).

\section{Para os militares, as editorias de economia represenfavam um espaço de menor risco porque as informações eram basicamente sobre o sefor público, e os dados e índices eram oficiais,}

fornecidos pelo BNDE, pelo CMN, pela Associação Comercial, pelas Federações das Indústrias, e, fundamentalmente, pelo Ministério da Fazenda (Abreu, 2001, p. 3).

Esse jornalismo acabou sendo utilizado como instrumento de divulgação da política econômica do regime militar, que buscava se legitimar diante dos governados, pela racionalidade da administração econômica - no governo Castelo Branco (gestão dos ministros Roberto Campos e Octávio Gouvêa de Bulhões) - e pela eficácia da economia e pelo 
desenvolvimento - durante os governos dos generais Arthur da Costa e Silva e Emílio Garrastazu Médici (gestão do ministro Delfim Neto).

Era importante que a imprensa divulgasse conquistas e avanços, já que a economia se tornara a moeda de legitimação de um regime sem legitimidade política. Não foi por acaso que, nos anos 1970, os jornais de maior prestígio e circulação no país criaram ou consolidaram suas editorias dedicadas a essa área (Abreu, 2003, p. 25).

O noticiário econômico era originário do Rio de Janeiro porque ali ficavam os ministérios da Fazenda e do Planejamento e os principais órgãos estatais. Mas a censura atingia todos os setores dos jornais, alguns com mais intensidade que outros.

\section{A modernização dos meios de comunicação foi, para os militares, parte de uma estrafégia política ligada à ideologia de segurança nacional.}

A implantação de um sistema de informação capaz de "integrar" o país compunha um projeto em que o Estado era entendido como o centro irradiador de todas as atividades fundamentais no campo político. Para concretização desse projeto, eles estimularam a formação de grandes redes, o que exigiu grandes investimentos. Foi nesse período que surgiram os oligopólios da informação, formados com recursos obtidos junto ao governo. Nos anos do regime militar, a imprensa, o rádio e televisão já dependiam fundamentalmente da publicidade para sobreviver e os maiores anunciantes eram as empresas estatais e instituições governamentais (Abreu, 2003, p. 23).

Um dos símbolos desse projeto foi a criação, em setembro de 1965, da Empresa Brasileira de Telecomunicações (Embratel), que deu início à instalação da rede básica de telecomunicações, implantando os sistemas de microondas em visibilidades e em tropodifusão na Amazônia (nesse caso ainda não era possível a transmissão de televisão, que só chegaria à região em 1975). Em 1965, foi também criado o Ministério das Comunicações e, em 1972, a Telecomunicações Brasileiras S.A. (Telebrás), empresa pública federal responsável pela coordenação dos serviços dessa área em todo o território nacional (Abreu; Lattman-Weltman, 2006, p. 73). ${ }^{10}$

Se, por um lado, os militares censuravam a imprensa e interferiam no conteúdo da informação, por outro, passaram a canalizar para a mídia grande massa de recursos, mediante financiamento e publicidade oficial, que beneficiaram os empresários da mídia.

Por meio do Grupo Executivo da Indústria de Papel e Artes Gráficas (Geipag), vinculado ao Ministério da Indústria e Comércio, e que tinha por objetivo analisar e aprovar os pedidos de importação de equipamentos gráficos, foram dadas facilidades para a obtenção de empréstimos em bancos oficiais e para a compra de equipamentos, o que permitiu a modernização das redações. Foram concedidos também financiamentos para a construção de novos prédios, necessários para abrigar novas máquinas e permitir a expansão das redações.

Com relação à publicidade dos órgãos oficiais, Abreu; Lattman-Weltman (2006, p. 75) lembram que aproximadamente $30 \%$ das receitas dos jornais eram obtidos dos clientes oficiais, o que significava uma dependência econômica considerável do Estado. Os proprietários dos meios de comunicação se submeteram à censura, em grande parte, devido a essa dependência, o que funcionou como amortecedor de uma possível oposição.

O jornalismo de economia atingiu a maioridade durante o regime militar não apenas devido à modernização da economia e à censura ao noticiário político, mas também por causa de novas necessidades e aspirações da classe média em ascensão, ávida por informações sobre opções de aplicações, investimentos e outros serviços, bem como por proteção contra o surto inflacionário que surgiu na esteira da decadência do "milagre" e prejudicou a economia do país no período pós-redemocratização.

\section{REFERÊNCIAS}

ABREU, Alzira. Jornalistas e editorias de economia. In: Encontro Anual da Compós, 10, 2001, Brasília. Grupo de Trabalhos Estudos de Jornalismo. Disponível em: $<$ www. facom.ufba.br/pos/compos_gtjornalismo/ home_2001.htm>. Acesso em: 25 set. 2003.

ABREU, Alzira A. Jornalistas e jornalismo econômico na transição democrática. In: ABREU, Alzira A. de; LATTMAN-WELTMAN, Fernando; KORNIS, Mônica 
Almeida. Mídia e Política no Brasil-jornalismo e fição. Rio de Janeiro: FGV, 2003.

ABREU, Alzira A.; LATTMAN-WELTMAN, Fernando. Uma instituição ausente nos estudos de transição: a mídia brasileira. In: ABREU, Alzira A. de (org). A democratizaçãa no Brasil - atores e contextos. Rio de Janeiro: FGV, 2006.

ALONSO, José Antônio Martínez. Dicionário de História do mundo contemporâneo. Espírito Santo: Instituto Histórico e Geográfico do Espírito Santo, 2000.

BAHIA, Juarez. Jornal, história e técnica: história da imprensa brasileira. v. I. São Paulo: Ática S.A., 1990.

CARVALHO, Samantha V. C. B. R. Internacionalização da midia brasileira: a trajetória da Gazeta Mercantil. 2001. Tese (Doutorado em Comunicação Social) Faculdade de Comunicação Social, Umesp. São Paulo, 2001.

KUCINSKI, Bernardo. Jornalismo econômico. São Paulo: Universidade de São Paulo, 2000.

LENE, Hérica. O jornalismo econômico ontem e hoje: resgate histórico de sua expansão no Brasil. In: $2^{\circ}$ Encontro Nacional da Rede Alfredo de Carvalho, 2004, Florianópolis.

LOUREIRO, Maria Rita. Os economistas no governo - gestão econômica e democracia. Rio de Janeiro: Fundação Getúlio Vargas, 1997.

MENDONÇA, Sônia Regina de; FONTES, Virgínia Maria. História do Brasil Recente - 1964-1992. 3 ed. São Paulo: Ática, 1994.

NASSIF, Luís. O cruzado - por dentro do choque. São Paulo: Livraria Cultura Editoria, 1986.

QUINTÃO, Aylê-Salassiê Figueiras. O jornalismo econômico no Brasil depois de 1964. Rio de Janeiro: Agir, 1987.

RAMADAN, Nancy Nuyen Ali. Jornalismo econômico de prestação de serviços e instituições financeiras: uma revisão necessária. 1995. Dissertação (Mestrado em Ciências da Comunicação), Escola de Comunicações e Artes da Universidade de São Paulo, 1995.

RIBEIRO, Ana Paula Goulart. Imprensa e história no Rio de Janeiro dos anos 50. Rio de Janeiro: E-papers, 2007.
SANDRONI, Paulo. Dicionário de Economia do século XXI. Rio de Janeiro: Record, 2005.

TASCHNER, Gisela. Folhas ao vento - análise de um conglomerado jornalístico no Brasil. Rio de Janeiro:Paz e Terra. 1992.

\section{NOTAS}

1 Esta abordagem integra a tese " $\mathrm{O}$ jornalismo de economia e a reinvenção do Brasil no final do século XX", defendida no Doutorado em Comunicação e Cultura da UFRJ em fevereiro de 2009. A pesquisa, desenvolvida com o apoio do CNPq, teve como objetivo compreender o processo de mudanças pelo qual passou o jornalismo de economia após a redemocratização, entre 1986 a 1999, a partir dos oito pacotes econômicos implementados no período.

${ }^{2}$ Para a elaboração da tese, foram realizadas entrevistas com três jornalistas de referência na cobertura de economia do país - Joelmir Beting, Luís Nassif e Miriam Leitão - e com atuação nos diferentes veículos de comunicação. As entrevistas com Beting e Nassif foram realizadas em São Paulo, no dia 26 de março de 2007, e a com Miriam Leitão foi no Rio de Janeiro, no dia 15 de maio do mesmo ano. Neste artigo, foram utilizados relatos dos dois primeiros pelo fato de terem abordado o jornalismo de economia na época da ditadura.

${ }^{3}$ Nesse período, desapareceram os seguintes jornais no Rio de Janeiro: A Noite, Correio da Manhã, O Jornal, Diário da Noite, Diário Carioca, Última Hora, Diário de Notícias, $O$ Radical, A Manhã, Folha Carioca e A Nação. E as revistas O Cruzeiro, Revista da Semana, Noite Ilustrada, Carioca e Vamos Ler pararam de circular. No novo contexto de concentração empresarial, periódicos como $O$ Globo e Jornal do Brasil se impuseram progressivamente (Ribeiro, 2007, p. 207-208).

${ }^{4} \mathrm{O}$ jornalista Aloysio Biondi atuou na imprensa brasileira na área de economia de 1967 até a sua morte, em julho de 2000.

${ }^{5}$ Período entre 1969 e 1973 (crise do petróleo), no qual a economia brasileira apresentou elevadas taxas de crescimento, viabilizadas pelas reformas fiscal e financeira implementadas após o golpe militar de 1964 (Alonso, 2000, p. 283).

${ }^{6} \mathrm{O}$ mercado de capitais é toda a rede de Bolsas de Valores e instituições financeiras (bancos, companhias de investimento e de seguro) que opera com compra e 
venda de papéis (ações, títulos de dívida em geral) em longo prazo. Tem a função de canalizar as poupanças da sociedade para o comércio, a indústria e outras atividades econômicas e para o próprio governo (Sandroni, 2005, p. 531).

${ }^{7}$ Comentarista de economia da TV Globo (desde 2007) e âncora da rádio CBN há mais de dez anos.

${ }^{8}$ Trecho da palestra "A transição no jornalismo econômico" proferida por Carlos Sardenberg em 24/11/1995 e publicada no site http://www.bancobrasil. com.br/appbb/portal/bb/si/pbcs/rsm/ CarlosAlbertoSad. jsp. Acesso em: 1 mai. 2004.

${ }^{9}$ Abreu (2003, p. 26), citando uma pesquisa realizada por Scavone, Belloni e Garbayo (1975), mostra que houve diminuição relativa das notícias de política nacional em benefício das notícias internacionais e econômicas, verificadas por meio de análise de conteúdo das matérias divulgadas na primeira página de dois jornais - o Jornal do Brasil e Última Hora - no período 1960-1971.

${ }^{10}$ A criação da Embratel, com um plano de estações repetidoras e canais de microondas, permitiu a formação e a consolidação das redes de TV no país. Embora o Brasil tivesse entrado na era da televisão em 1950, só a partir da década de 1970 a TV se tornaria um veículo de comunicação de massa. Foi com a entrada no mercado da TV Globo, em 1965, que ocorreu a grande transformação da TV no país - é quando ela se torna uma grande empresa capitalista (Abreu \& Lattman-Weltman, 2006, p. 73). 